AperTO - Archivio Istituzionale Open Access dell'Università di Torino

Finance, Labour, Capital, and International Integration

This is a pre print version of the following article:

Original Citation:

Availability:

This version is available http://hdl.handle.net/2318/1597347

since 2016-09-29T15:10:46Z

Published version:

DOI: $10.1111 /$ manc. 12158

Terms of use:

Open Access

Anyone can freely access the full text of works made available as "Open Access". Works made available under a Creative Commons license can be used according to the terms and conditions of said license. Use of all other works requires consent of the right holder (author or publisher) if not exempted from copyright protection by the applicable law. 


\title{
Finance, Labour, Capital, and International Integration
}

\author{
Giuseppe Bertola * \\ EDHEC Business School, \\ Università di Torino, \\ CEPR, CESifo.
}

March 2016

The Manchester School, forthcoming

\begin{abstract}
Labour incomes depend on structural as well as politico-economic factors, because labour market policies partially remedy the financial market imperfections that make labour income shocks difficult to insure, and have different implications for labour and capital income. This paper illustrates such theoretical insights with a simple model, and reviews evidence of their empirical relevance generated by international economic, monetary, and financial integration.
\end{abstract}

JEL: D33, J38.

* This paper illustrates and reviews issues covered by the author's keynote at the Money, Macro and Finance Research Group 47 $7^{\text {th }}$ Annual Conference (9 September 2015, Cardiff Business School). It benefits from comments received on that occasion. 


\section{Introduction}

Policies that introduce rigidities in earning determination and labour allocation are often blamed for reducing employment and productivity. If policymakers are willing and able to implement them, however, those policies must trade those effects off others that are in their eyes beneficial. Lower employment and productivity may be a reasonable price to pay for smoothing the labour income shocks that cannot be insured by imperfect and incomplete financial markets. If it were possible to write and enforce fully contingent labour contracts, in fact, workers and employers could circumvent policy constraints by signing side contracts that effectively offset any legal provision (Lazear, 1990). Because financial markets are imperfect and incomplete, labour income is exposed to uninsurable shocks, side contracts meant to circumvent legislation are not enforceable, and policy can influence labour market outcomes in potentially beneficial ways. In an imperfect world, however, labour policies redistribute income and welfare across population groups that rely more or less strongly on labour incomes. Hence observed policies maximize, under structural constraints, politically controversial objectives.

This paper illustrates the practical relevance of these general points for theoretical and empirical research. Section 2 introduces a stylized labour market policy in a very simple economy, and analyzes its effects for labour allocation and factor income distribution. Section 3 extends the model to let a factor other than labour be in elastic supply, reducing the effectiveness and political desirability of the model's labour policy. Section 4 discusses how this and related theoretical mechanisms make it possible for empirical work to exploit international economic integration as a source of quasi-experimental variation in the constraints facing national policymakers, and to establish the realism of a politico-economic perspective that, as briefly discussed in Section 5, may prove useful to policymakers as well as to further research. 


\section{Labour and finance}

Incomplete and asymmetric information generally makes it impossible to write and enforce labour contracts that distinguish the implications of exogenous shocks from those of unobservable individual behaviour. Policies that reduce the volatility of net labour incomes (hence the negative welfare impact of uninsurable shocks) also reduce labour reallocation and effort (hence equilibrium productivity). They can be welfare-improving, because laissez-faire markets need not optimize the trade-off between higher effort and consumption stability. But they need not benefit everybody, because their welfare implications differ across ex-ante heterogeneous individuals.

To illustrate these points simply, consider an economy where each individual is endowed with a unit of labour that can be allocated to a default occupation with constant productivity $w_{0}$, or to higher-paying jobs that require an unobservable effort or investment $\operatorname{cost} x$ and are subject to uninsurable shocks: each worker who has paid an income-equivalent amount $x$ earns $w_{1}+\varepsilon$, where $\varepsilon$ is a random shock with variance $\sigma^{2}$ and zero mean. ${ }^{1}$

Let individual objective functions be linear in the expectation and variance of income, with negative relative weight $v$ on the latter. Then, workers are indifferent between the two employment opportunities when $w_{1}-v \sigma^{2}-x=w_{0}$. Modelling individual workers' choice between safe and risky jobs in terms of a mean-variance trade-off makes it possible to apply standard financial insights to human capital assets, which not only expose individuals to

\footnotetext{
${ }^{1}$ At the cost of slightly more complicated notation and derivations it is possible to let returns be decreasing and risky in both employment opportunities, as in Bertola (2014), and/or interpret the default occupation as untaxed leisure.
} 
uninsurable risk but are also indivisible: each individual must allocate all labour to a specific job

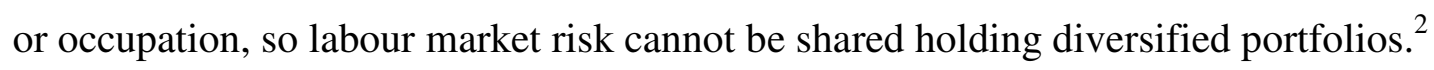

To outline the implications of labour policies, let all labour incomes be subject to a proportional tax at rate $t$, the revenue of which is rebated equally to all workers. In this simple model economy, where all individuals have the same labour endowment, the redistribution scheme corresponds to progressive taxation and redistribution of their different labour incomes. It implications, however, are qualitative similar to those of the many real-life policies that smooth incomes and influence labour allocation, including unemployment insurance, employment protection legislation, and collective bargaining and legal constraints on wage volatility (Agell, 2002).

In equilibrium, individuals should be indifferent between earning $(1-t) w_{0}$ with certainty and paying $x$ to earn the random income $(1-t)\left(w_{1}+\varepsilon\right)$. As both the mean and variance of risky income are influenced by proportional taxation, the indifference condition $(1-t) w_{1}-$ $(1-t)^{2} \sigma^{2} v-x=(1-t) w_{0}$ implies an expected wage differential

$$
w_{1}-w_{0}=(1-t) v \sigma^{2}+\frac{\mathrm{x}}{1-t} \equiv w_{D}(t)
$$

between risky and safe jobs.

${ }^{2}$ A mean-variance objective can be more rigorously micro-founded assuming normally distributed shocks and constant absolute risk aversion utility function (Bertola, 2014), which is also amenable to explicitly dynamic treatments (Shimer and Werning, 2008). More accurate analysis of redistribution's welfare implications would take into account higher-order utility impacts (Chetty, 2006). 
The tax-financed subsidy is not random if idiosyncratic shocks cancel out across workers, and when $l(t)$ labour units choose risky jobs it amounts to $\left(l(t) w_{1}+(1-l(t)) w_{0}\right) t=$ $\left(l(t) w_{D}+w_{0}\right) t$. Normalizing to unity the total number of labour units, and adding the subsidy to net wages,

$$
w_{0}+l(t) w_{D} t \equiv y_{L}(t)
$$

is labour's income-equivalent contribution to the typical individual's welfare. As long as (1) holds with equality, all labour earns incomes that are in welfare terms equivalent to the riskless default option (2). In the $t=0$ laissez faire equilibrium, $y_{L}(0)=w_{0}$, a constant independent of labour allocation in this simple model. This makes it particularly easy to discuss the implications of the policy represented by $t$ : while at $t=0$ the returns to human capital investment are competed away in equilibrium, $t>0$ not only smoothes out labour income shocks but also lets all labour units partake of the returns to human capital investment.

Even though redistribution takes place only across labour incomes, $t$ influences the economy's aggregate output, because the average productivity and riskiness of labour incomes is endogenously determined by human capital investment choices. For condition (1) to pin down labour allocation, in fact, $w_{1}$ should be a decreasing function of the number $l$ of labour units allocated to high-return, high-risk employment opportunities, which therefore generate inframarginal income over and above payments to labour on the basis of its marginal productivity. To see this, it is simplest to work with the linear functional form $w_{1}=w_{0}+\alpha-$ $\beta l$, for $\alpha>0$ and $\beta>0$, so that condition (1) identifies the relationship

$$
l(t)=\left(\alpha-w_{D}(t)\right) / \beta
$$

between high-productivity employment and the policy parameter $t$. 
Figure 1 shows, for the parameters listed above it, how $t$ influences labour allocation and incomes. The marginal productivity schedule meets the vertical axis at $\alpha$, and its $-\beta$ slope reflects horizontal lines into vertical lines that meet the horizontal axis at the employment level (3). For each $t$ the figure draws two horizontal lines. The higher one meets the vertical axis at $w_{D}(t)$, and with the corresponding vertical line delimits a rectangle of area $\left(\alpha-w_{D}(t)\right) w_{D}(t) / \beta$. A portion $t$ of it, below the lower horizontal line, represents the excess over $\mathrm{w}_{0}$ of labour's unit net income (2), which is

$$
y_{L}(t)=w_{0}+\frac{\left(\alpha-w_{D}(t)\right) w_{D}(t)}{\beta} t
$$

in the linear-quadratic case. Production also includes the area

$$
\frac{\left(\alpha-w_{D}(t)\right)^{2}}{2 \beta} \equiv y_{R}(t)
$$

of the triangles above each rectangle, which corresponds to rents accruing to owners of the fixed factors that account for decreasing returns in production. Like the labour income subsidy, this income is not random if the factors that produce it are traded in a financial market where idiosyncratic risk can be fully diversified.

In Figure 1 the wage differential $w_{D}(t)$ declines as $t$ grows from zero to 0.2 , increases back to its laissez faire level as $t$ reaches 0.4 , and grows further for $t=0.6$. To see why it is not monotonic, consider how the two additive terms of expression (1) depend on $t$. The first, $(1-t) v \sigma^{2}$, is decreasing, because a larger $t$ redistributes idiosyncratic shocks across lucky and unlucky workers, reduces labour income uncertainty, and lets a smaller expected wage differential support labour allocation to risky jobs. However, the subsidy is not contingent on the riskiness of employment, and human capital investment is not deductible from taxable income: 
this is appropriate if individual labour market behaviour cannot be observed, and implies that the policy redistributes income from individuals who invest $x$ and expose their income to random shocks, to those who just earn the default income. Lower private rewards to human capital investment explain why the second term $x /(1-t)$ in $(1)$ is an increasing function of $t$.

The first effect dominates the second for small $t$ if $v \sigma^{2}>x$, as in the figure. In reality, imperfections of labour and financial market make some policy interventions obviously beneficial. In this simple model, as long as $v \sigma^{2}>x$ uninsurability of labour income unambiguously implies that at least some redistribution of labour incomes is warranted. For the same parameters as in Figure 1, the top panel of Figure 2 plots (4) and (5) along with their sum. All welfare expressions are increasing for small $t$, because they assign positive weight to $t$ and negative weight to the square of $t$.

Each hump-shaped expression begins to decline at points marked by a dot in the figure. The tax rate that maximizes rents is lower than the one that maximizes labour's welfare. In Figure 1, in fact, rent triangles are maximized when $t$ minimizes $w_{D}(t)$ : differentiating (5), this is the case when $w_{D}^{\prime}(t)=0$ and

$$
t_{R}^{*}=1-\sqrt{x /\left(v \sigma^{2}\right)}
$$

Incomes earned by factors other than labour are maximal when policy minimizes the wage differential, plotted in the bottom panel of Figure 2, and maximizes allocation of complementary labour to the decreasing-returns sector.

The optimal $t$ from this point of view is approximately $20 \%$ for the parameters used to plot the figures. It clearly does not maximize the welfare yield of a unit of labour, which by (2) depends not on total production, but on how much of the excess over $w_{0}$ of labour's productivity 
is paid to labour. In Figure 1, the area of the rectangle that represents labour welfare at the minimum wage differential $w_{D}\left(t_{R}^{*}\right)$ is larger than at $w_{D}(0)$, but smaller than that implied by raising $t$ further, to let more intense redistribution reduce the risk-equivalent component of a larger human capital investment cost. In the top panel of Figure 2, labour welfare grows beyond $t=20 \%$, until it peaks at $t$ about $38 \%$.

The maximum of $y_{L}(t)+y_{R}(t)$, the economy's total risk- and investment-adjusted income, is reached at a $t$ value which is of course intermediate between that which maximizes $y_{L}(t)$ and that which maximizes $y_{R}(t)$. Maximization of aggregate income does not provide a very solid reference point for either normative or positive purposes if individuals income sources are heterogeneous and utility cannot be transferred across them by direct transfers, or by redefining factor property rights, but only through the distortive policies parameterized by $t$.

The model predicts that $t$ should not be observed in regions where its variation would benefit all agents. For the parameters used in the figures, it should not be lower than 0.2 (else, increasing it would raise both labour and other incomes) or higher than 0.38 (else, it would be unambiguously beneficial to decrease it). Within those bounds, however, different $t$ values are preferred by individuals who derive income from labour and other factors in different proportions, and the model's positive predictions are not independent of the weight attached in political decisions to labour policy's allocative and distributional implications.

The policy targets labour income uninsurability, a financial market imperfection, using an instrument that has different collateral effects for individuals who own different amounts of diversifiable financial wealth, and are therefore more or less intensely affected by labour income risk. Figure 3 illustrates this simple insight plotting a weighted sum of labour and non-labour 
income, $y_{L}(t)+s y_{R}(t)$, for various values of $s$. This expression corresponds to aggregate or average income when $s=1$, to that of individuals who are entitled to different amounts of nonlabour income for other values of $s$. Welfare is an increasing function of the individual nonhuman wealth index $s$, and is maximized by smaller values of $t$ as $s$ increases from zero (a pure worker) towards infinity (an individual whose labour yields a negligible fraction of total income).

Among Pareto-optimal policies, the one that is implemented is that preferred by politically decisive individuals. In reality, and in theoretical models where uninsurable labour income shocks are smoothed by self-insuring accumulation and decumulation of savings, wealth is more concentrated than labour incomes. The simple model introduced in this section implies that a larger $t$ should be observed in societies where policy is chiefly determined by a majority of relatively poor workers, than in societies where wealth confers more political power to richer individuals.

\section{Policy and capital}

Consider next the implications for the policy-choice problem of allowing non-labour income to include not only rents (paid to exogenously given factors, such as land) but also payments to a factor (such as financial capital) that is competitively supplied. Continuing to work with linear and quadratic functional forms, let the expected value of labour's productivity in jobs that require an investment and expose workers to uninsurable risk be

$$
w_{1}=w_{0}+\alpha+\delta k_{1}-\beta l,
$$


where $k_{1}$ denotes employment of capital in the risky-jobs sector of the economy, and a positive $\delta$ lets it be complementary to labour in production. If capital's unit income is determined by a marginal productivity schedule with negative slope (normalized to unity),

$$
y_{K}=\delta l-k_{1},
$$

then subtracting payments to labour and capital from the total production corresponding to these marginal productivity schedules yields rents,

$$
y_{R}=\frac{\beta}{2} l^{2}+\frac{1}{2} k_{1}{ }^{2}-\delta k_{1} l .
$$

If $k_{1}=k$ is given, distinguishing rents from capital income only changes notation without altering the model's implications. All insights from the above derivations and illustrations remain qualitatively valid when capital income and (9) replace the similarly quadratic expression (5) as the analytical counterpart of Figure 1's triangles, and $\alpha+\delta k$ replaces $\alpha$ so that, by the indifference condition (1),

$$
l(t ; k)=\frac{\alpha+\delta k-w_{D}(t)}{\beta} .
$$

If instead $k_{1}$ adjusts endogenously to ensure that $y_{K}=r$, inserting $k_{1}=\delta l-r$ in (7) and imposing (1) yields

$$
l(t ; r)=\frac{\alpha-\delta r-w_{D}(t)}{\beta-\delta^{2}} .
$$

Expressions (10) and (11) differ in two respects: the constant term of labour's marginal productivity schedule declines when $k$ is replaced by $-r$; and employment responds more strongly to $w_{D}(t)$ when $\delta>0$, because the marginal productivity of capital is kept constant by capital inflows or outflows that also shift the marginal product of complementary labour. This 
illustrates simply the more general fact that, under very mild and plausible conditions, endogenous adjustment of other production factors increases the elasticity of labour demand.

These expressions make it easy to characterize the welfare yield of labour units (4), which is

$$
y_{L}(t ; k)=w_{0}+\frac{\left(\alpha+\delta k-w_{D}(t)\right) w_{D}(t)}{\beta} t
$$

if the stock of capital is fixed at $k_{1}=k$, and

$$
y_{L}(t ; r)=w_{0}+\frac{\left(\alpha-\delta r-w_{D}(t)\right) w_{D}(t)}{\beta-\delta^{2}} t
$$

if $k_{1}$ adjusts to keep the marginal product of capital fixed at $r$.

Even in this simple model welfare depends in fairly intricate ways on the implications of capital endogeneity for capital use, for labour demand's slope, and for policy determination. The model's simple structure and functional forms however make it easy to characterize the policy implications that are of particular interest here. As discussed above, policy generally maximizes with respect to $t$ some weighted combination of the labour welfare measure, in the form (10) or (11), and of rents and capital income, in (8) and (9).

Because other factors benefit from employment of complementary labour, their income is maximal when $l$ is as large as possible, i.e., when policy minimizes $w_{D}$. As in (1), this depends only on human capital investment costs and labour income risk, and he right-hand panels of Figure 4 show that non-labour income is maximized by the $t$ value in (6) regardless of whether $k_{1}$ is fixed or adjusts endogenously. In top-left panel of Figure 4, conversely, endogeneity of capital does influence labour's welfare-maximizing $t$, which is intuitively lower when smaller rents may be captured for labour by taxation and redistribution of wage differentials. Formally, 
both (10) and (11) depend on $t$ only through the numerator of their second term, where elastic capital supply replaces $k$ with $-r$. Standard comparative static methods establish that an expression in the form $\left(x-w_{D}(t)\right) w_{D}(t) t$ is maximized by a larger $t$ if $x$ is larger, as long as $\left(x-w_{D}(t)\right)>0$, which must be the case if $l>0$, and $w_{D}^{\prime}(t)>0$. If policy only maximized production and non-labour income, then it would set $w^{\prime}(t)=0$. If labour's welfare has positive weight in the policymaker's objective function, however, then $w^{\prime}{ }_{D}(t)>0$ at the optimum, and endogeneity of capital reduces the optimal $t$.

\section{International economic integration}

In the model exemplified above, and in the related models briefly reviewed in what follows, the configuration and implications of labour policy depend on political and structural factors in arguably sensible and potentially observable ways.

At given values of the model's parameters, for example, larger values of $t$ within the admissible region imply higher production and more volatile labour incomes, tracing a familiar trade-off between productivity and ex-post inequality. To assess the realism of such relationships, it is possible to exploit observable time-series and cross-country variation of policies, of their determinants, and of the outcomes they target. The simple model above, however, also shows that this is no easy task in practice. When aiming to characterize productivity-inequality trade-offs, for example, one should recognise that policy depends not only on political factors (summarized in the model by the weight of labour welfare in policy objectives, $s$ in Figure 3) but also on some of the same structural parameters that also influence

productivity and inequality (such as the human capital investment cost, $x$, and the intensity $\sigma^{2}$ and welfare impact $v$ of labour income risk). 
Empirical work must identify plausibly exogenous sources of policy variation, and disentangle the exogenous from the policy-induced portion of outcome variation. It is of course simplest to view policy variation as exogenous, supposing that it is mostly driven by changes of political sentiment rather than by structural changes. This assumption may be empirically plausible in specifications that control for structural variation with country-specific features and/or fixed effects. A model that embeds a labour market similar to that discussed above in a dynamic consumption problem under constant absolute risk aversion predicts that labour market deregulation, represented by a decrease of $t$ in the model and by combinations of policy indicators in the data, implies not only faster growth but also higher uncertainty, hence stronger savings motives and larger current account surpluses (Bertola and Lo Prete, 2015). Data spanning the period from the early 1990s until the 2008 crisis confirm that labour market deregulation was broadly associated with current account surpluses, and that the association was stronger when and where underdeveloped financial markets made it difficult to smooth the consumption and welfare implications of labour income volatility. Not only international trade deficits, but also policies and financial development are principle endogenous. Unfortunately, it is much easier to specify and characterize theoretical models where financial market imperfections, financial transaction volumes, and public consumption-smoothing policies all depend on deep parameters than to identify empirical counterparts for those structural factors. Interactions of global time effects with country-specific historical and geographical characteristics of each country, however, are potentially relevant and plausibly exogenous drivers of trade intensity, financial development, and government policies: this approach yields fairly strong and substantively interesting empirical results in a broad panel of countries (Bertola and Lo Prete, 2013). 
International economic integration makes it possible for this research to detect empirically the motivation and effects of policies, because it alters in observable ways the trade-offs facing country-level policy-makers. In the model discussed in the previous section it is particularly easy to analyse the role in this respect of financial openness. The model's country is financially autarkic when its available stock of capital determines $k_{1}$, and fully integrated in international markets when $k_{1}$ is endogenously set to ensure that $\delta l-k_{1}=r$. The total income plotted in the bottom-left panel of Figure 4 rewards all its capital stock $k$ at rate $r$, and corresponds to national income when capital can be invested in (or borrowed from) other countries. Because capital flows exploit gains from trade, they cannot decrease national income in laissez faire. Their effects are more complicated in the presence of distortionary policies. But only their interaction with policy influences welfare and incomes in Figure 4, because the parameters are such that the economy's marginal return to capital would coincide with $r$ at $t=0$, so that in the absence of policy financial integration would be unconsequential.

As in Figure 3, policy generally gives different weight to labour and other types of income. Should policy be chosen so as to maximize aggregate income in Figure 4, integration would leave it broadly unaffected, but result in a lower $t$; should it only target the labour welfare plotted in the top-left panel of Figure 4, then integration would result in a sharper decline, from a higher level, of the policy parameter $t$. Such policy preferences are generally difficult to disentangle from structural heterogeneity, but the model's functional form assumptions let integration influence policy choices in sharply different ways for labour and other incomes, and make it particularly straightforward to characterize the intuitive and empirically helpful role of capital in determining policy in laissez faire and the policy impact of financial integration. Figure 5 plots welfare before and after integration for the same parameter values used in previous pictures, and 
three different values of the economy's $k$. In autarky, larger values of $k$ are associated with higher labour and fixed-factor incomes, lower capital incomes, and higher optimal tax rates from the point of view of labour income earners: as discussed above, redistribution is more appealing when larger rents may be captured, and standard comparative static methods establish that labour's optimal $t$ is increasing in the intercept of linear labour demand schedules. The policy implemented in the model economy generally depends on the weight attached to labour incomes rather than to capital or fixed-factor income's preferred $t$, which is again independent of capital intensity. As long as policy does attach positive weight to labour income, however, higher capital endowments imply a sharper fall of $t$ when capital mobility removes capital stocks as a source of policy heterogeneity.

While the interaction of financial integration and policy is easy to characterise in theory, in practice the empirical implications of heterogeneous and gradual financial integration may be difficult to disentangle from those of country-specific structural or political trends. Europe's Economic and Monetary Union (EMU), however, provides an opportunity to observe crosscountry labour reform patterns in a setting where each country's political preferences and structural parameters may plausibly be treated as constant over a period when, as evidenced by large international financial imbalances, the elasticity of capital supply in each country was suddenly and dramatically increased by adoption of a common currency. EMU changed the circumstances in which national policy is made, but arguably left unchanged its political motives and other country-specific factors, and labour policy data do offer significant support to the model's politico-economic perspective on labour policies. Across EMU countries, the deregulation detected in early EMU by the European Commission's LABREF data (Turrini et al., 2015) and by other indicators was much stronger in capital-abundant and capital-exporting 
"core" countries, such as Germany, than in "peripheral" countries, such as Spain. The latter in fact experienced not only strong capital inflows and investment booms, but also some tightening of labour market regulation, which would be surprising from a simple race-to-the-bottom perspective but is qualitatively consistent with the implications of an explicit model of policy competition among countries of different capital intensity and size (Bertola 2016). ${ }^{3}$

\section{Concluding comments}

Much of this paper consists of straightforward derivations, intuitive illustrations, and simple formal results that do not need to be summarized, but illustrate practical implications of the simple idea that financial market imperfections and economic integration interact with political processes in determining labour policies. The resulting insights are positive rather than normative, but do have simple substantive implications for research and policy design.

Accurate physics models not only help describe accurately the orbits of planets around stars, but also make it possible to design successful space-crafts. Similarly, politico-economic models of the motivation and implications of labour market policies not only help understand the

${ }^{3}$ The model in Bertola (2016), while closely related, differs from to that studied here in some key respects. Its constant-elasticity functions do not accommodate additive labour income uncertainty as easily as the linear functions analysed here and in Bertola (2014), but make it possible to characterize policy in terms of decisive individuals' preferences. In autarky, these are a simple closed-form function of their endowments of capital and of labour, which in that model is supplied with less than infinite elasticity and earns the country-specific rents attributed here to owners of a generic country-specific fixed factor. 
reforms triggered by economic integration, but also may help design policies that suitably shape and accompany international economic integration processes.

To interpret and influence policy developments, economic research should aim to explain how and why reality deviates from the theoretical paradigm of perfect and complete financial markets. In an imperfect reality, markets and policies not only maximize production, but also resolve conflicting interests in its distribution, and the policy reforms triggered by new circumstances have both desirable and undesirable effects. Just as it would have been impossible to reach the moon ignoring the law of gravity, so it can be disastrous to disregard the need to address labour policy issues when liberalizing international financial markets. 


\section{References}

Agell, Jonas (2002). 'On the Determinants of Labour Market Institutions: Rent Seeking vs. Social Insurance', German Economic Review 3(2) pp. 107-135.

Bertola, G. (2014). 'Labour Market Policies and European Crises', IZA Journal of Labour Policy 3:5 doi:10.1186/2193-9004-3-5.

Bertola, Giuseppe (2016). 'Labour Policies and Capital mobility in Theory and in EMU', European Economic Review doi:10.1016/j.euroecorev.2016.04.007

Bertola, G, and Lo Prete, A. (2013). 'Finance, Governments, and Trade', Review of World Economics 149, pp.273-294.

Bertola, G, and Lo Prete, A. (2015). 'Reforms, Finance, and Current Accounts', Review of International Economics 23(3) pp. 469-488.

Chetty, R. (2006). 'A general formula for the optimal level of social insurance', Journal of Public Economics 90 pp. 1879-1901.

Lazear, Edward P. (1990). 'Job Security Provisions and Employment', Quarterly Journal of Economics 105 pp. 699-726.

Shimer, R. and Werning, I. (2008). 'Liquidity and Insurance for the Unemployed' American Economic Review 98:5, pp. 1922-1942.

Turrini, A., Koltay, G., Pierini, F., Goffard, C., and Kiss, A. (2015). 'A Decade of Labour Market Reforms in the EU: Insights from the LABREF database' IZA Journal of Labour Policy 4:12 doi:10.1186/s40173-015-0038-5. 


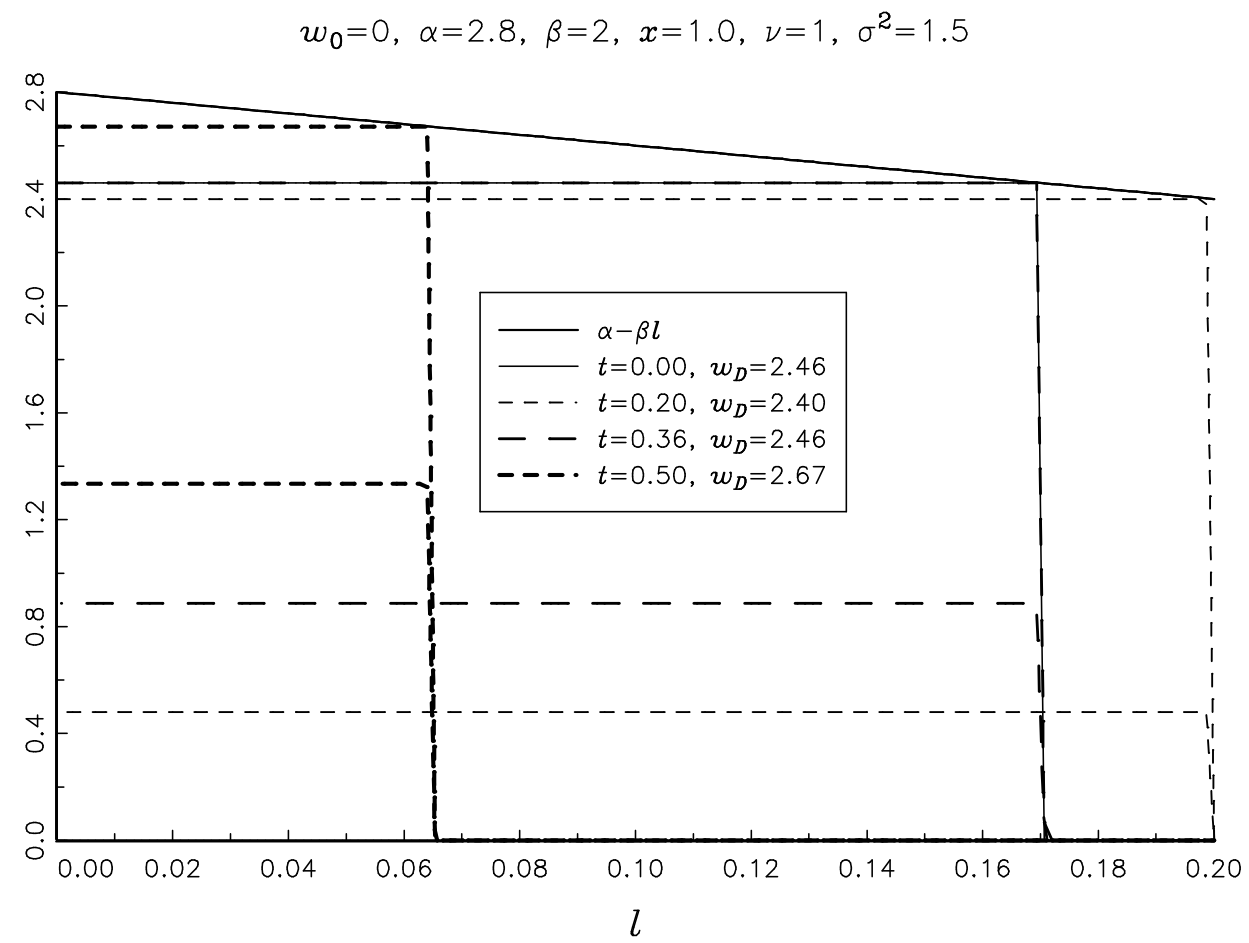

Figure 1. Implications of labour policy for employment (on the horizontal axis) and incomes (areas of rectangles). 

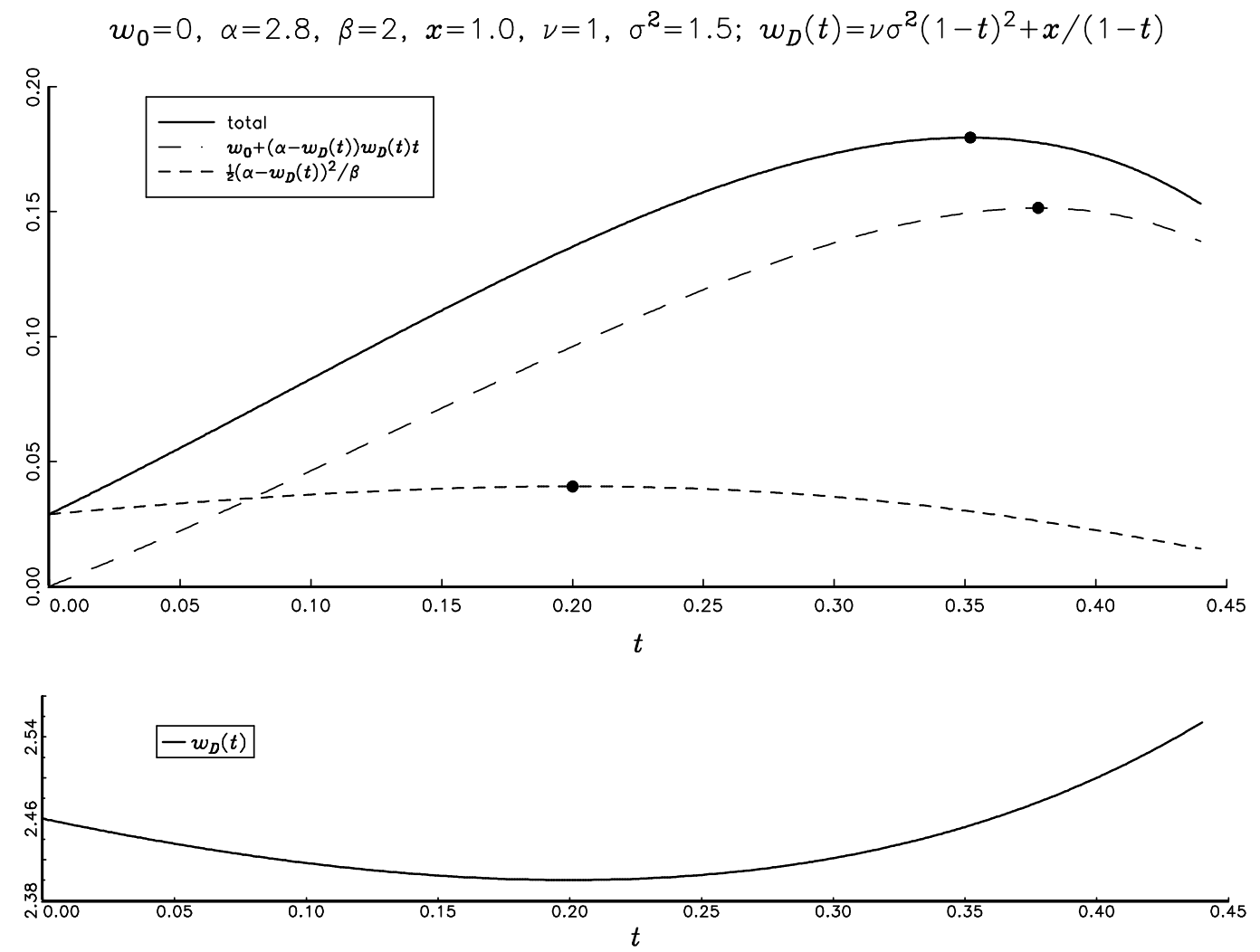

Figure 2. Implications of labour policy for labour and other incomes (top panel) and for wage differential between default and higher-productivity occupations (bottom panel). 


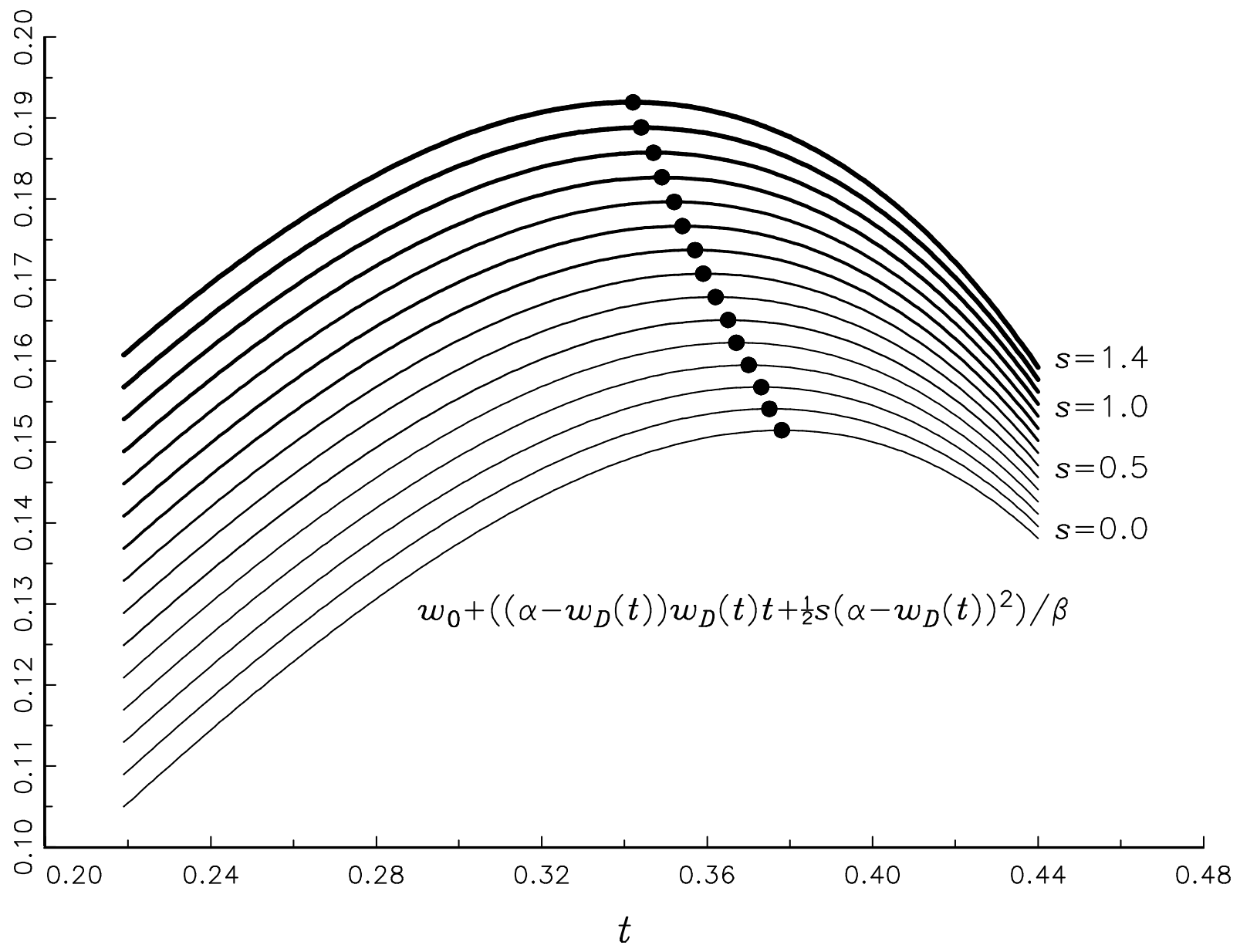

Figure 3. Implications of labour policy for the welfare of individuals entitled to different amounts of non-labour income. 

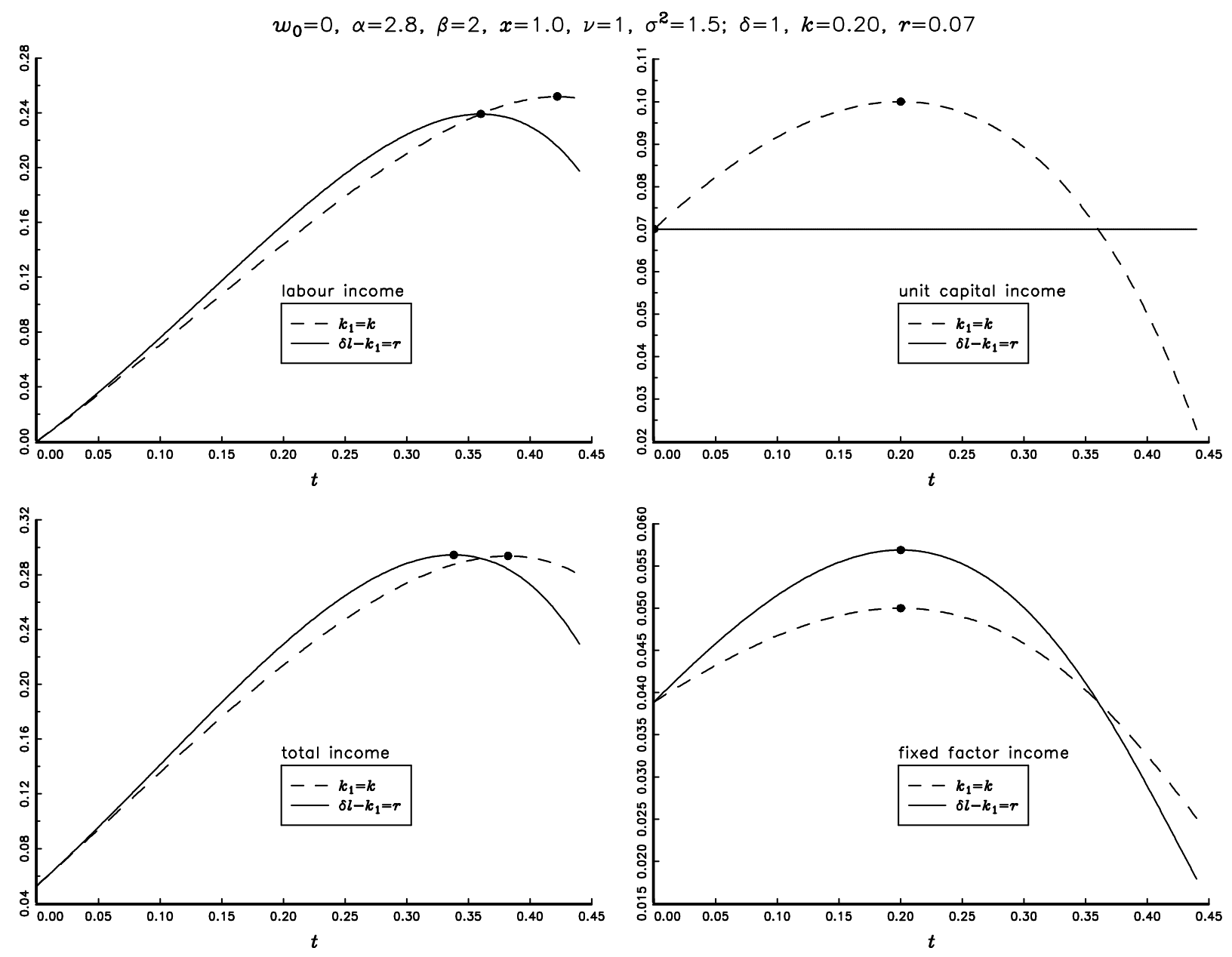

Figure 4. Implications of labour policy for labour welfare and other incomes when capital is fixed (dashed line) or supplied elastically to keep its marginal productivity constant (solid line). 

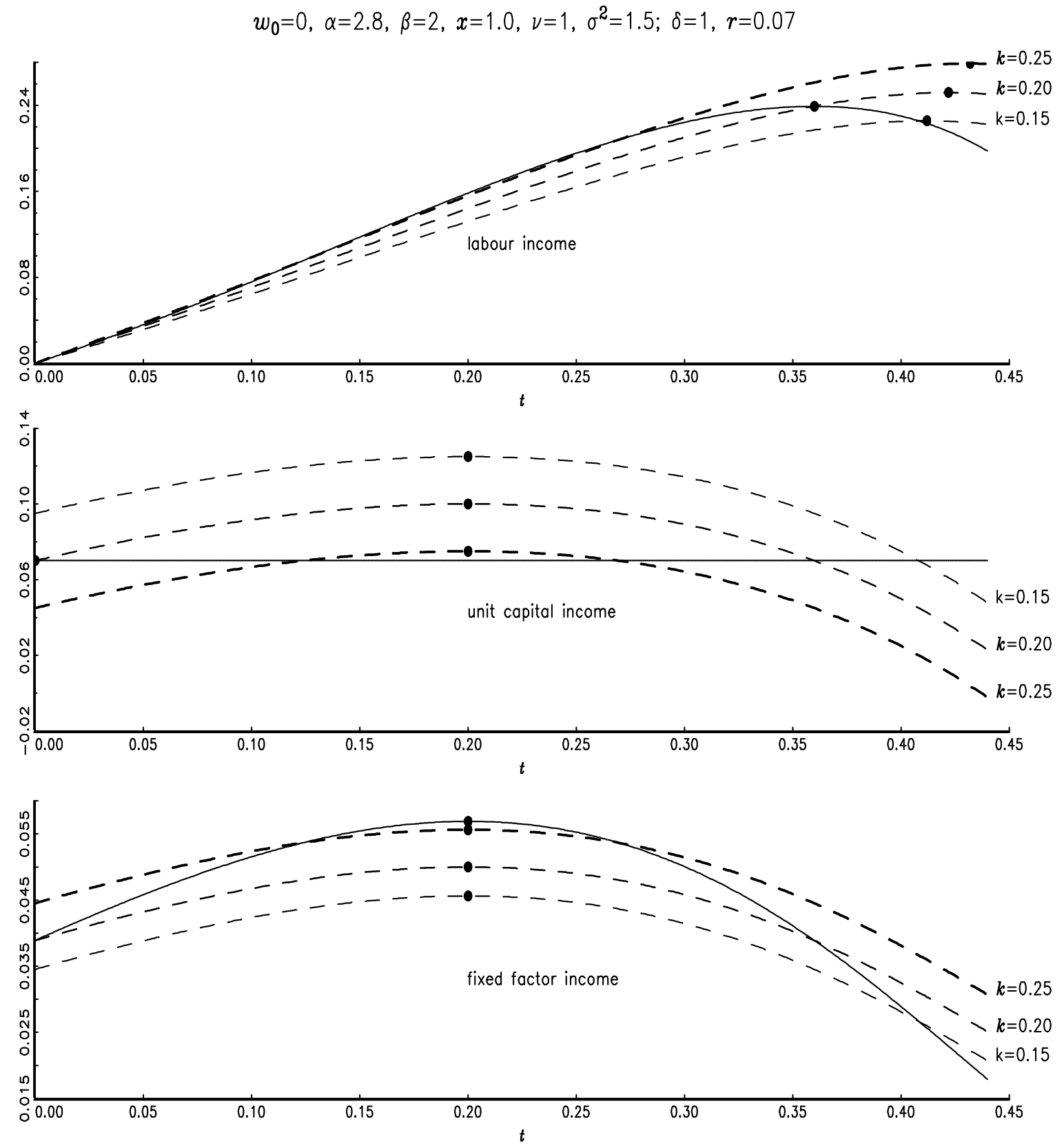

Figure 5. Implications of policy for labour welfare and other incomes when capital is available in various fixed amounts (dashed lines) or supplied elastically to keep its marginal productivity constant (solid line). 